\title{
Intelligent Selection of Machining Parameters in Multipass Turnings Using Firefly Algorithm
}

\author{
Abderrahim Belloufi, ${ }^{1,2}$ Mekki Assas, ${ }^{1}$ and Imane Rezgui ${ }^{2}$ \\ ${ }^{1}$ Laboratoire de Recherche en Productique (LRP), Département de Génie Mécanique, Université Hadj Lakhder, 05000 Batna, Algeria \\ ${ }^{2}$ Département de Génie Mécanique, Université Kasdi Merbah Ouargla, 30000 Ouargla, Algeria \\ Correspondence should be addressed to Abderrahim Belloufi; abelloufi@yahoo.fr
}

Received 26 July 2013; Accepted 1 October 2013; Published 9 February 2014

Academic Editor: Mingcong Deng

Copyright (c) 2014 Abderrahim Belloufi et al. This is an open access article distributed under the Creative Commons Attribution License, which permits unrestricted use, distribution, and reproduction in any medium, provided the original work is properly cited.

Determination of optimal cutting parameters is one of the most important elements in any process planning of metal parts. In this paper, a new optimization technique, firefly algorithm, is used for determining the machining parameters in a multipass turning operation model. The objective considered is minimization of production cost under a set of machining constraints. The optimization is carried out using firefly algorithm. An application example is presented and solved to illustrate the effectiveness of the presented algorithm.

\section{Introduction}

The selection of optimal cutting parameters, like the number of passes, depth of cut for each pass, feed, and speed, is a very important issue for every machining processes [1].

Several cutting constraints must be considered in machining operations. In turning operations, a cutting process can possibly be completed with a single pass or by multiple passes. Multipass turning is preferable over single-pass turning in the industry for economic reasons [2].

The optimization problem of machining parameters in multipass turnings becomes very complicated when plenty of practical constraints have to be considered [3].

Traditionally, mathematical programming techniques like graphical methods [4], linear programming [5], dynamic programming $[6,7]$, and geometric programming $[8,9]$ had been used to solve optimization problems of machining parameters in multipass turnings. However, these traditional methods of optimization do not fare well over a broad spectrum of problem domains. Moreover, traditional techniques may not be robust. Numerous constraints and multiple passes make machining optimization problems complicated and hence these techniques are not ideal for solving such problems as they tend to obtain a local optimal solution.
Thus, metaheuristic algorithms have been developed to solve machining economics problems because of their power in global searching. There have been some works regarding optimization of cutting parameters [2, 3, 10-14] for different situations; authors have been trying to bring out the utility and advantages of genetic algorithm, evolutionary approach, and simulated annealing. It is proposed to use the new optimization technique, firefly algorithm, for the machining optimization problems.

The firefly algorithm (FA) is a metaheuristic, natureinspired, and optimization algorithm which is based on the social (flashing) behavior of fireflies, or lighting bugs, in the summer sky in the tropical temperature regions [5-18]. It was developed by Dr. Yang at Cambridge University in 2007, and it is based on the swarm behavior such as fish, insects, or bird schooling in nature. In particular, although the firefly algorithm has many similarities with other algorithms which are based on the so-called swarm intelligence, such as the famous Particle Swarm Optimization (PSO), Artificial Bee Colony optimization (ABC), and Bacterial Foraging algorithms (BFA), it is indeed much simpler both in concept and implementation $[15,16,18,19]$. Furthermore, according to recent bibliography, the algorithm is very efficient and can outperform other conventional algorithms, such as genetic 
algorithms, for solving many optimization problems, a fact that has been justified in a recent research, where the statistical performance of the firefly algorithm was measured against other well-known optimization algorithms using various standard stochastic test functions [20].

The current paper focuses on the application of a new optimization technique, firefly algorithm, to determine the optimal machining parameters that minimize the unit production cost in multipass turnings.

\section{Cutting Process Model}

2.1. Decision Variables. In the constructed optimization problem, six decision variables are considered: cutting speeds in rough and finish machining $\left(V_{r}, V_{s}\right)$, feed rates in rough and finish machining $\left(f_{r}, f_{s}\right)$, and depth of cut for each pass of rough and finish machining $\left(a_{r}, a_{s}\right)$.

2.2. Objective Function. Based on the minimum unit production cost, UC, criterion, the objective function for a multipass turning operation can be given by the equation [10]:

$$
\begin{gathered}
\mathrm{UC}=C_{M}+C_{I}+C_{R}+C_{T}, \\
C_{M}=k_{0}\left[\frac{\pi D L}{1000 V_{r} f_{r}}\left(\frac{a_{t}-a_{s}}{a_{r}}\right)+\frac{\pi D L}{1000 V_{s} f_{s}}\right], \\
C_{I}=k_{0}\left[t_{c}+\left(h_{1} L+h_{2}\right)\left(\frac{a_{t}-a_{s}}{a_{r}}+1\right)\right], \\
C_{R}=k_{0} \frac{t_{c}}{T_{p}}\left[\frac{\pi D L}{1000 V_{r} f_{r}}\left(\frac{a_{t}-a_{s}}{a_{r}}\right)+\frac{\pi D L}{1000 V_{s} f_{s}}\right], \\
C_{T}=\frac{k_{t}}{T_{p}}\left[\frac{\pi D L}{1000 V_{r} f_{r}}\left(\frac{a_{t}-a_{s}}{a_{r}}\right)+\frac{\pi D L}{1000 V_{s} f_{s}}\right] .
\end{gathered}
$$

2.3. Constraints. There are some constraints which affect the selection of the optimal cutting conditions and will be taken into account.

The constraints in rough and finish machining are as outlined below [10].

\subsubsection{Rough Machining}

Parameter Bounds. Due to the limitations on the machine and cutting tool and due to the safety of machining the cutting parameters are limited with the bottom and top permissible limit:

$$
\begin{gathered}
\text { cutting speed: } V_{r L} \leq V_{r} \leq V_{r U}, \\
\text { feed rate: } f_{r L} \leq f_{r} \leq f_{r U}, \\
\text { depth of cut: } a_{r L} \leq a_{r} \leq a_{r U}
\end{gathered}
$$

Tool-Life Constraint. The constraint on the tool life is taken as

$$
T_{L} \leq T_{r} \leq T_{U}
$$

Cutting Force Constraint. The maximum amount of cutting forces Fu should not exceed a certain value as higher forces produce shakes and vibration. This constraint is given below:

$$
F_{r}=k_{1}\left(f_{r}\right)^{\mu}\left(a_{r}\right)^{v} \leq F_{u} .
$$

Power Constraint. The nominal power of the machine $P_{U}$ limits the cutting process:

$$
P_{r}=\frac{F_{r} V_{r}}{6120 \eta} \leq P_{U},
$$

efficiency $\eta=0.85$.

Stable Cutting Region Constraint. This constraint is given as

$$
\left(V_{r}\right)^{\lambda} f_{r}\left(a_{r}\right)^{\nu} \geq \mathrm{SC} .
$$

Chip-Tool Interface Temperature Constraint. This constraint is given as

$$
Q_{r}=k_{2}\left(V_{r}\right)^{\tau}\left(f_{r}\right)^{\phi}\left(a_{r}\right)^{\delta} \leq Q_{u}
$$

2.3.2. Finish Machining. All the constraints other than the surface finish constraint are similar for rough and finish machining [21].

Surface Finish Constraint. In the finishing operations, the obtained surface roughness must be smaller than the specified value, $\mathrm{SR}_{U}$, given by technological criteria, so that the following equation is satisfied:

$$
\frac{f_{s}^{2}}{8 R} \leq \mathrm{SR}_{U}
$$

Constraints for roughing and finishing parameter relations are

$$
\begin{aligned}
& V_{s} \geq k_{3} V_{r}, \\
& f_{r} \geq k_{4} f_{s}, \\
& a_{r} \geq k_{5} a_{s} .
\end{aligned}
$$

The Number of Rough Cuts. The possible number of rough cuts is restricted by

$$
n=\frac{a_{t}-a_{s}}{a_{r}}
$$

where $n_{L} \leq n \leq n_{U}$,

$$
\begin{aligned}
& n_{L}=\frac{\left(a_{t}-a_{s U}\right)}{a_{r U}}, \\
& n_{U}=\frac{\left(a_{t}-a_{s L}\right)}{a_{r L}} .
\end{aligned}
$$

The optimization problem in multipass turnings can be divided into $m=\left(n_{U}-n_{L}+1\right)$ subproblems, in each of which the number of rough cuts $n$ is fixed. So the solution of the whole optimization problem is divided into searching the optimal results of $m$ subproblems and the minimum of them is the objective of whole optimization problem [3]. 


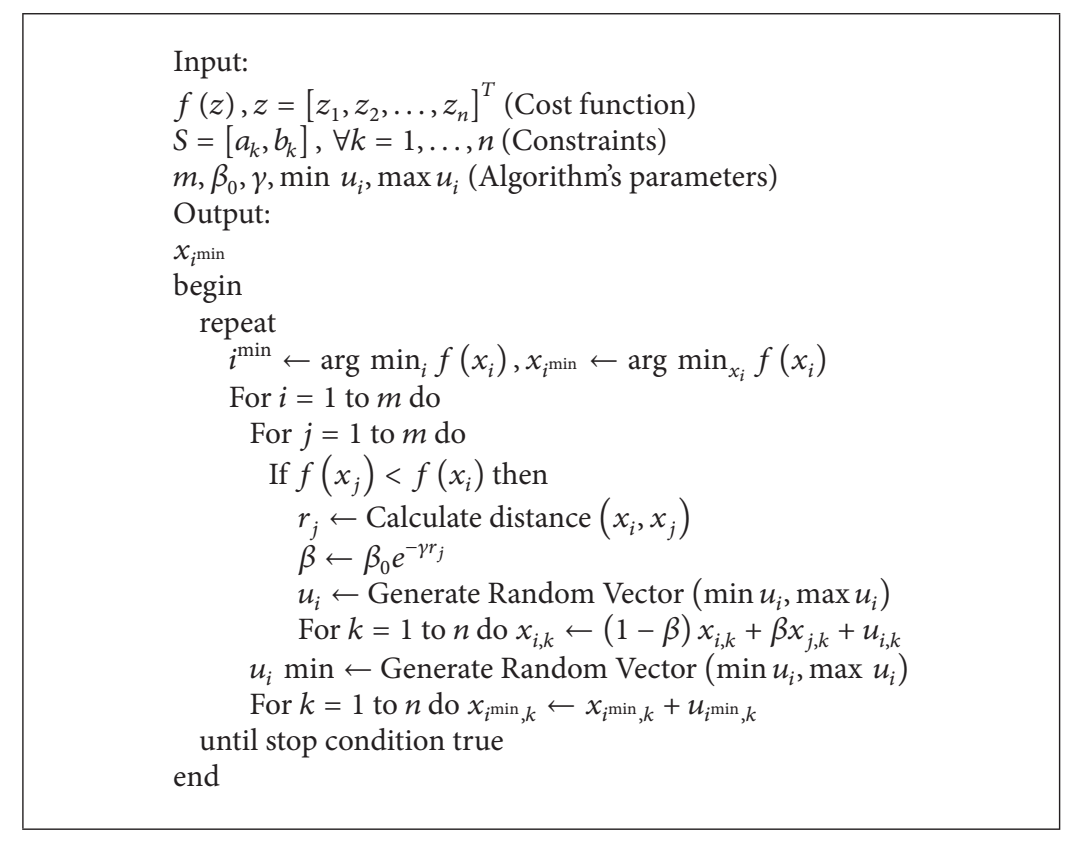

Pseudocode 1

\section{Firefly Algorithm (FA)}

Firefly algorithm is inspired by biochemical and social aspects of real fireflies. Real fireflies produce a short and rhythmic flash that helps them in attracting (communicating) their mating partners and also serves as protective warning mechanism. FA formulates this flashing behavior with the objective function of the problem to be optimized. The following three rules are idealized for basic formulation of FA.

(i) All fireflies are unisex so that fireflies will attract each other regardless of their sex.

(ii) Attractiveness is proportional to their brightness, which decreases as distance increases between two flies. Thus the less bright one will move towards the brighter one. In case it is unable to detect brighter one it will move randomly.

(iii) The brightness of a firefly is determined by the landscape of the objective function.

3.1. Firefly Algorithm Concept [17]. The algorithm is considered in the continuous constrained optimization problem setting where the task is to minimize cost function $f(x)$ for $x \in S \subset \mathbb{R}^{n}$; that is, find $x^{*}$ such that:

$$
f\left(x^{*}\right)=\min _{x \in S} f(x) .
$$

Assume that there exists a swarm of $m$ agents (fireflies) solving optimization problem iteratively and $x_{i}$ represents a solution for a firefly $i$ in algorithm's iteration $k$, whereas $f\left(x_{i}\right)$ denotes its cost.

Each firefly has its distinctive attractiveness $\beta$ which implies how strong it attracts other members of the swarm. As a firefly attractiveness one should select any monotonically decreasing function of the distance $r_{j}=d\left(x_{i}, x_{j}\right)$ to the chosen firefly $j$, for example, as Yang suggests, the exponential function:

$$
\beta=\beta_{0} e^{-\gamma r_{j}},
$$

where $\beta_{0}$ and $\gamma$ are predetermined algorithm parameters: maximum attractiveness value and absorption coefficient, respectively.

Every member of the swarm is characterized by its light intensity $I_{i}$ which can be directly expressed as an inverse of a cost function $f\left(x_{i}\right)$.

Initially all fireflies are dislocated in $S$ (randomly or employing some deterministic strategy).

To effectively explore considered search space $S$ it is assumed that each firefly $i$ is changing its position iteratively taking into account two factors: attractiveness of other swarm members with higher light intensity, that is, $I_{j}>I_{i}$, for all $j=1, \ldots, m, j \neq i$, which is varying across distance and a fixed random step vector $u_{i}$.

If no brighter firefly can be found only the randomized step is being used.

\subsection{Pseudocode of the Firefly Algorithm. See Pseudocode 1.}

\section{Application Example}

Now an application example is considered to demonstrate and validate the firefly algorithm (FA) for the optimization of process parameters of the multipass turning operation. The parameters used for the numerical application are mentioned in Table 1.

4.1. Results and Discussion. The Firefly algorithm was run with these parameters: 
TABLE 1: Machining data [10].

\begin{tabular}{|c|c|c|c|c|c|}
\hline Parameter & Values & Parameter & Values & Parameter & Values \\
\hline$D(\mathrm{~mm})$ & 50 & $L(\mathrm{~mm})$ & 300 & $a_{t}(\mathrm{~mm})$ & 6 \\
\hline$V_{r U}(\mathrm{~m} / \mathrm{min})$ & 500 & $V_{r L}(\mathrm{~m} / \mathrm{min})$ & 50 & $f_{r U}(\mathrm{~mm} / \mathrm{rev})$ & 0.9 \\
\hline$f_{r L}(\mathrm{~mm} / \mathrm{rev})$ & 0.1 & $a_{r U}(\mathrm{~mm})$ & 3.0 & $a_{r L}(\mathrm{~mm})$ & 1.0 \\
\hline$V_{s U}(\mathrm{~m} / \mathrm{min})$ & 500 & $V_{s L}(\mathrm{~m} / \mathrm{min})$ & 50 & $f_{s U}(\mathrm{~mm} / \mathrm{rev})$ & 0.9 \\
\hline$f_{s L}(\mathrm{~mm} / \mathrm{rev})$ & 0.1 & $a_{s U}(\mathrm{~mm})$ & 3.0 & $a_{s L}(\mathrm{~mm})$ & 1.0 \\
\hline$P$ & 5 & $q$ & 1.75 & $r$ & 0.75 \\
\hline$k_{1}$ & 108 & $\mu$ & 0.75 & $v$ & 0.95 \\
\hline$\eta$ & 0.85 & $\lambda$ & 2 & $v$ & -1 \\
\hline$k_{2}$ & 132 & $\tau$ & 0.4 & $\phi$ & 0.2 \\
\hline$\delta$ & 0.105 & $R(\mathrm{~mm})$ & 1.2 & $k_{0}(\$ / \min )$ & 0.5 \\
\hline$C_{0}$ & $6 \times 10^{11}$ & $h_{1}$ & $7 \times 10^{-4}$ & $h_{2}$ & 0.3 \\
\hline$T_{L}(\min )$ & 25 & $t_{c}(\mathrm{~min} / \mathrm{piece})$ & 0.75 & $t_{e}(\mathrm{~min} /$ edge $)$ & 1.5 \\
\hline$P_{U}(\mathrm{~kW})$ & 5 & $T_{U}(\min )$ & 45 & $F_{u}(\mathrm{~N})$ & 1961.3 \\
\hline SC & 140 & $\mathrm{SR}_{U}(\mu \mathrm{m})$ & 10 & $Q_{u}\left({ }^{\circ} \mathrm{C}\right)$ & 1000 \\
\hline$k_{3}$ & 1.0 & $k_{4}$ & 2.5 & $k_{5}$ & 1.0 \\
\hline$k_{t}$ (\$/edge) & 2.5 & & & & \\
\hline
\end{tabular}

TABLE 2: The optimized turning parameters.

\begin{tabular}{ccccccc}
\hline$n$ & \multicolumn{2}{c}{ Cutting parameters (rough machining) } & \multicolumn{3}{c}{ Cutting parameters (finish machining) } \\
& $V_{r}(\mathrm{~m} / \mathrm{min})$ & $f_{r}(\mathrm{~mm} / \mathrm{rev})$ & $a_{r}(\mathrm{~mm})$ & $V_{s}(\mathrm{~m} / \mathrm{min})$ & $f_{s}(\mathrm{~mm} / \mathrm{rev})$ & $a_{s}(\mathrm{~mm})$ \\
\hline 1 & 98.4102 & 0.8200 & 3.0000 & 162.2882 & 0.2582 & 3.0000 \\
2 & 145.7281 & 0.6067 & 2.3964 & 207.0844 & 0.1519 & 1.2072 \\
3 & 144.1821 & 0.7907 & 1.5958 & 191.9014 & 0.1590 & 2.7213 \\
4 & 145.8086 & 0.7886 & 1.2429 & 180.1447 & 0.1821 & 1.2125 \\
5 & 166.5327 & 0.8998 & 1.0000 & 191.3605 & 0.2582 & 1.0285 \\
\hline
\end{tabular}

TABLE 3: Results of optimization using different algorithms.

\begin{tabular}{lcc}
\hline \multicolumn{1}{c}{ Algorithms } & & Unit cost (\$) \\
\hline FEGA & {$[2]$} & 2.3084 \\
SA/SP & {$[3]$} & 2.2795 \\
PSO & {$[10]$} & 2.2721 \\
GA & {$[11]$} & 2.2538 \\
SS & {$[12]$} & 2.0754 \\
GA-based approach & {$[13]$} & 2.0298 \\
ACO & {$[14]$} & 1.9680 \\
Firefly & & 1.9358 \\
\hline
\end{tabular}

$$
\begin{aligned}
& \mathrm{nf}=40 \text { (number of fireflies) } \\
& \alpha=0.25 \text { (randomness) } \\
& \beta_{0}=0.20 \text { (minimum value of beta), } \\
& \gamma=1 \text { (Absorption coefficient). }
\end{aligned}
$$

The results found by the Firefly algorithm are mentioned on Table 2.

We find that the lowest value is $1.9358 \$$ under which the minimum number of rough cuts $n=1$ is taken.

The performance of the Firefly algorithm and others can be seen in Table 3.
According to Table 3 one notices that the firefly algorithm yields much better results than the other algorithms. Thus the firefly algorithm can tackle the optimization of multipass turning operations problem efficiently to achieve better results in reducing the unit production cost.

\section{Conclusion}

This paper presents a firefly algorithm optimization for solving the multipass turning operations problem. The results obtained from comparing the Firefly algorithm with those taken from recent literature prove its effectiveness.

The results of the Firefly algorithm are compared with results of genetic algorithms, simulated annealing, particle swarm intelligence, scatter search, and ant colony approaches.

The firefly algorithm obtains near optimal solution; it can be used for machining parameter selection of complex machined parts that require many machining constraints. Also, it can be extended to solve the other metal cutting optimization problems such as milling and drilling.

\section{Abbreviations}

$C_{I}$ : Machine idle cost due to loading and unloading operations and tool idle motion time (\$/piece)

$C_{M}$ : Cutting cost by actual time in cut (\$/piece) 


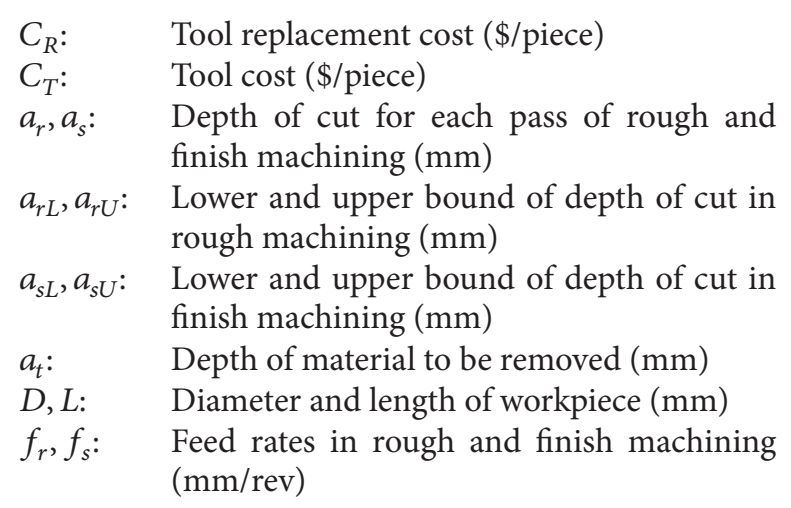

$f_{r L}, f_{r U}$ : Lower and upper bound of feed rate in rough machining ( $\mathrm{mm} / \mathrm{rev})$

$f_{s L}, f_{s U}:$ Lower and upper bound of feed rate in finish machining $(\mathrm{mm} / \mathrm{rev})$

$F_{r}, F_{s}$ : Cutting forces during rough and finish machining $(\mathrm{N})$

$F_{u}: \quad$ Maximum allowable cutting force (N)

$h_{1}, h_{2}$ : Constants related to cutting tool travel and approach/departure time ( $\mathrm{min})$

$k_{0}$ : $\quad$ Direct labor cost plus overhead ( $\left.\$ / \mathrm{min}\right)$

$k_{t}$ : $\quad$ Cutting edge cost (\$/edge)

$k 1, \mu, v$ : Constants of cutting force equation

$k_{2}, \tau, \phi, \delta$ : Constants related to chip-tool interface temperature equation

$k_{3}, k_{4}, k_{5}$ : Constants for roughing and finishing parameter relations

$\lambda, v: \quad$ Constants related to expression of stable cutting region

$n: \quad$ Number of rough cuts (an integer)

$N_{U}, N_{L}$ : Upper and lower bounds of $n$

$p, q, r, C_{0}$ : Constants of tool-life equation

$P_{r}, P_{s}$ : Cutting power during rough and finish machining $(\mathrm{kW})$

$P_{U}$ : $\quad$ Maximum allowable cutting power $(\mathrm{kW})$

$Q_{r}, Q_{s}: \quad$ Chip-tool interface rough and finish machining temperatures $\left({ }^{\circ} \mathrm{C}\right)$

$Q_{U}$ : Maximum allowable chip-tool interface temperature $\left({ }^{\circ} \mathrm{C}\right)$

$q: \quad$ A weight for $T_{p}[0,1]$

$R: \quad \quad$ Nose radius of cutting tool $(\mathrm{mm})$

SC: $\quad$ Limit of stable cutting region constraint

$\mathrm{SR}_{U}$ : Maximum allowable surface roughness $(\mathrm{mm})$

$T, T_{r}, T_{s}$ : Tool life, expected tool life for rough machining, and expected tool life for finish machining ( $\mathrm{min})$

$T_{p}: \quad$ Tool life of weighted combination of $T_{r}$ and $T_{s}$ (min)

$T_{U}, T_{L}: \quad$ Upper and lower bounds for tool life (min)

UC: $\quad$ Unit production cost except material cost (\$)

$V_{r}, V_{s}$ : Cutting speeds in rough and finish machining $(\mathrm{m} / \mathrm{min})$

$V_{r L}, V_{r U}$ : Lower and upper bound of cutting speed in rough machining $(\mathrm{m} / \mathrm{min})$

$V_{s L}, V_{s U}$ : Lower and upper bound of cutting speed in finish machining $(\mathrm{m} / \mathrm{min})$.

\section{Conflict of Interests}

The authors declare that there is no conflict of interests regarding the publication of this paper.

\section{References}

[1] R. Quiza Sardiñas, M. Rivas Santana, and E. Alfonso Brindis, "Genetic algorithm-based multi-objective optimization of cutting parameters in turning processes," Engineering Applications of Artificial Intelligence, vol. 19, no. 2, pp. 127-133, 2006.

[2] Y.-C. Wang, "A note on 'optimization of multi-pass turning operations using ant colony system," International Journal of Machine Tools and Manufacture, vol. 47, no. 12-13, pp. 20572059, 2007.

[3] S. Xie and Y. Guo, "Intelligent selection of machining parameters in multi-pass turnings using a GA-based approach," Journal of Computational Information Systems, vol. 7, no. 5, pp. 17141721, 2011.

[4] S. Engin Kiliç, C. Cogun, and D. Tayyar Şen, "A computeraided graphical technique for the optimization of machining conditions," Computers in Industry, vol. 22, no. 3, pp. 319-326, 1993.

[5] D. S. Ermer and D. C. Patel, "Maximization of production rate with constraints by linear programming and sensitivity analysis," in Proceedings of the 2nd North American Metalworking Research Conference (WI '74), 1974.

[6] J. S. Agapiou, "The optimization of machining operations based on a combined criterion-part 2: multipass operations," Journal of Engineering for Industry, vol. 114, no. 4, pp. 508-513, 1992.

[7] Y. C. Shin and Y. S. Joo, "Optimization of machining conditions with practical constraints," International Journal of Production Research, vol. 30, no. 12, pp. 2907-2919, 1992.

[8] E. D. Ermer, "Optimization of the constrained machining economics problem by geometric programming," ASME Journal of Engineering for Industry, vol. 93, no. 4, pp. 1067-1072, 1971.

[9] P. G. Petropoulos, "Optimal selection of machining rate variable by geometric programming," International Journal of Production Research, vol. 11, no. 4, pp. 305-314, 1973.

[10] M.-C. Chen and D.-M. Tsai, "A simulated annealing approach for optimization of multi-pass turning operations," International Journal of Production Research, vol. 34, no. 10, pp. $2803-$ 2825, 1996.

[11] M.-C. Chen and K.-Y. Chen, "Optimization of multipass turning operations with genetic algorithms: a note," International Journal of Production Research, vol. 41, no. 14, pp. 3385-3388, 2003.

[12] J. Srinivas, R. Giri, and S.-H. Yang, "Optimization of multi-pass turning using particle swarm intelligence," International Journal of Advanced Manufacturing Technology, vol. 40, no. 1-2, pp. 5666, 2009.

[13] R. S. Sankar, P. Asokan, R. Saravanan, S. Kumanan, and G. Prabhaharan, "Selection of machining parameters for constrained machining problem using evolutionary computation," International Journal of Advanced Manufacturing Technology, vol. 32, no. 9-10, pp. 892-901, 2007.

[14] M.-C. Chen, "Optimizing machining economics models of turning operations using the scatter search approach," International Journal of Production Research, vol. 42, no. 13, pp. 26112625, 2004.

[15] X. S. Yang, Nature-Inspired Meta-Heuristic Algorithms, Luniver Press, Beckington, UK, 2008. 
[16] S. Lukasik and S. Zak, "Firefly algorithm for continuous constrained optimization tasks," in Proceedings of the International Conference on Computer and Computational Intelligence (ICCCI '09), N. T. Nguyen, R. Kowalczyk, and S. M. Chen, Eds., vol. 5796 of LNAI, pp. 97-106, Springer, Wroclaw, Poland, October 2009.

[17] X. S. Yang, "Firefly algorithms for multimodal optimization," in Proceedings of the Stochastic Algorithms: Foundations and Applications (SAGA '09), vol. 5792 of Lecture Notes in Computing Sciences, pp. 178-178, Springer, Sapporo, Japan, October 2009.

[18] X. S. Yang, "Firefly algorithm, stochastic test functions and design optimization," International Journal of Bio-Inspired Computation, vol. 2, no. 2, pp. 78-84, 2010.

[19] X. S. Yang, "Firefly algorithm, levy flights and global optimization," in Research and Development in Intelligent Systems XXVI, pp. 209-218, Springer, London, UK, 2010.

[20] T. Apostolopoulos and A. Vlachos, "Application of the firefly algorithm for solving the emissions load dispatch problem," International Journal of Combinatorics, vol. 2011, Article ID 523806, 23 pages, 2011.

[21] K. Vijayakumar, G. Prabhaharan, P. Asokan, and R. Saravanan, "Optimization of multi-pass turning operations using ant colony system," International Journal of Machine Tools and Manufacture, vol. 43, no. 15, pp. 1633-1639, 2003. 

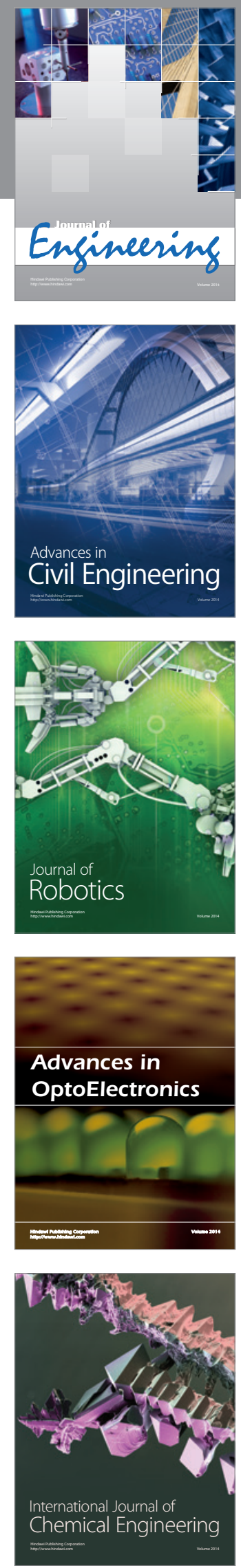

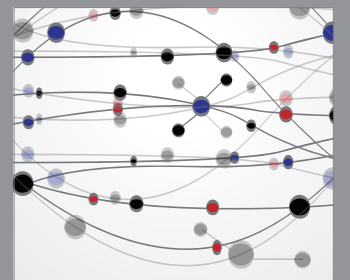

The Scientific World Journal
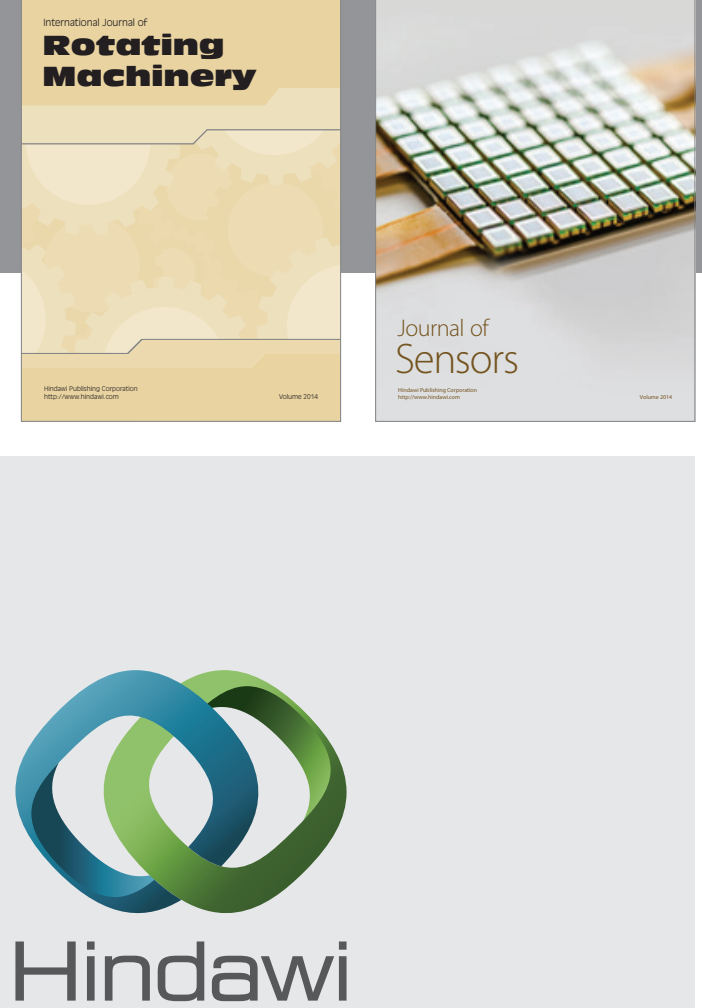

Submit your manuscripts at http://www.hindawi.com
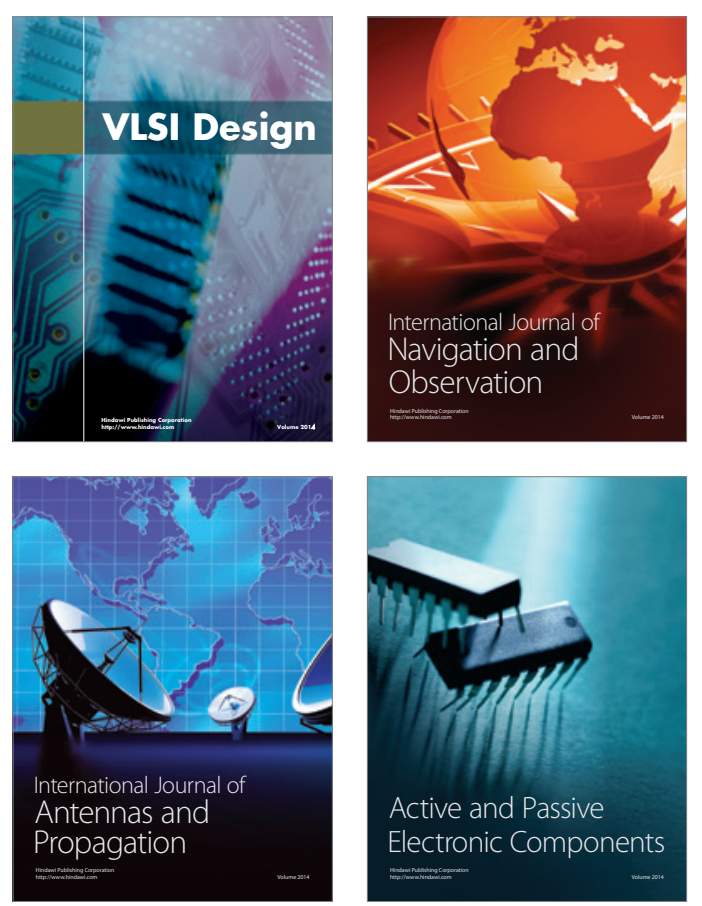
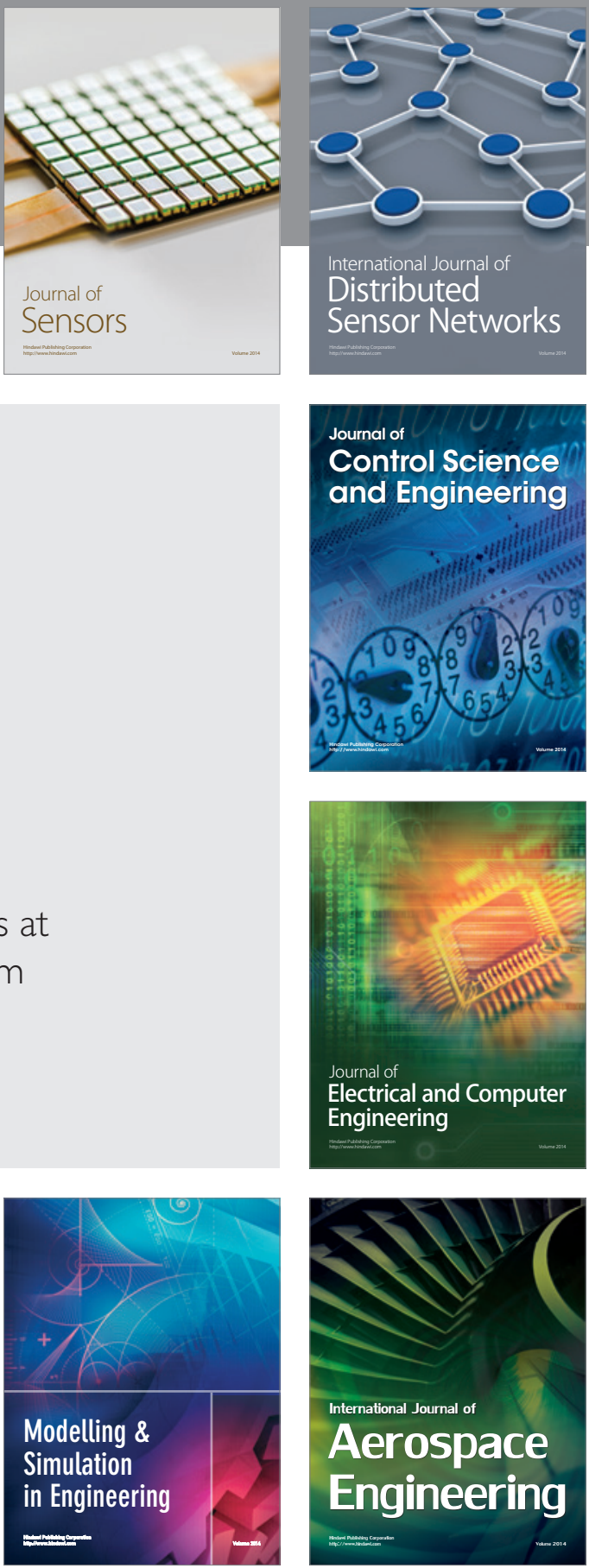

Journal of

Control Science

and Engineering
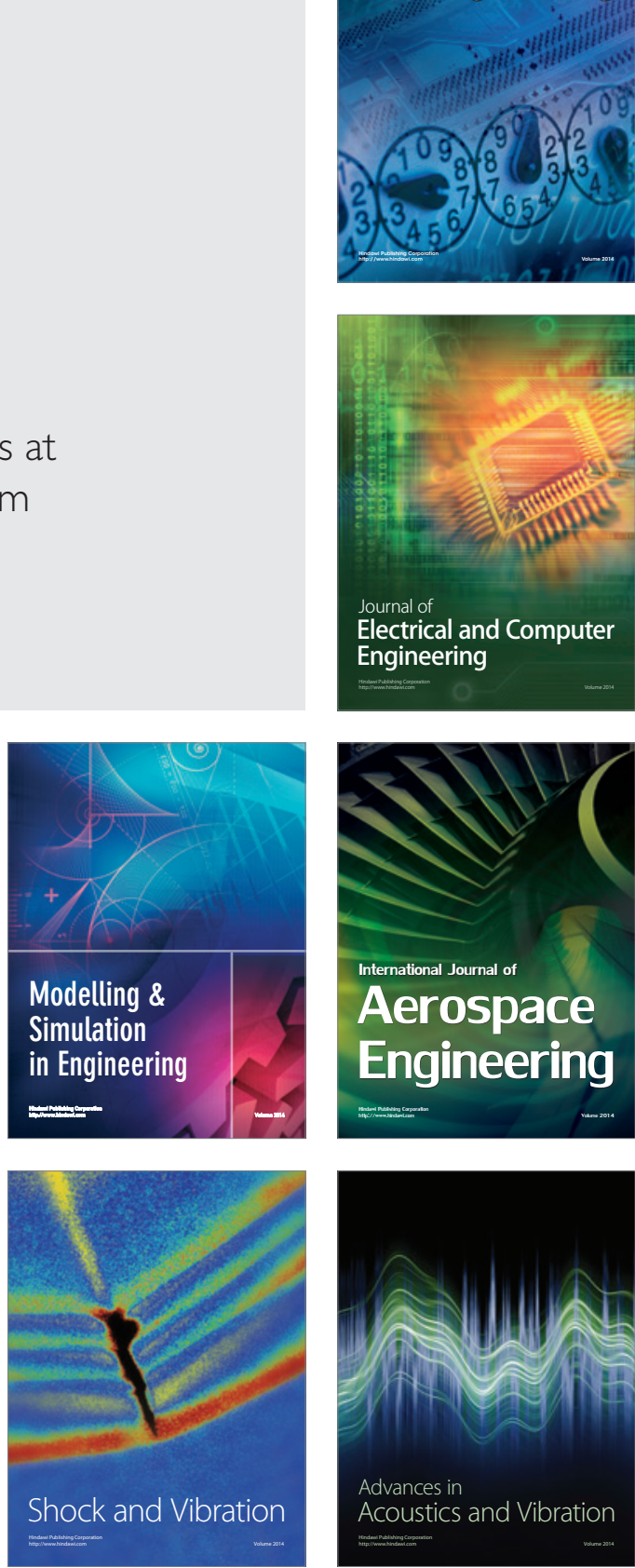